\title{
REDUÇÃO DA INTERFERÊNCIA DE Brachiaria decumbens NA FORMAÇÃO de Pastagem COM Penisetum purpureum AtraVés de Herbicidas ${ }^{1}$
}

\author{
Reduction of Brachiaria decumbens Interference on Pennisetum purpureum Pasture \\ Establishment Through Herbicides
}

\begin{abstract}
SILVA, W. ${ }^{3}$, VILELA, D., PEREIRA, A.V. ${ }^{3}$, FERREIRA, F.A. ${ }^{4}$ e FERREIRA, R.P. ${ }^{3}$
RESUMO - A tolerância da gramínea forrageira capim-elefante a herbicidas aplicados isoladamente ou em misturas entre si, aplicados em condições de pré e pós-emergência da forrageira, bem como a eficiência desses produtos no controle de $B$. decumbens e outras espécies de plantas daninhas, foram avaliadas em dois experimentos. Os herbicidas aplicados no experimento conduzido em condições de pré-emergência do capim-elefante, com as respectivas doses em $\mathrm{kg} \mathrm{ha}^{-1}$, foram: metolachlor $(1,152 ; 2,304$; e 3,456), oxyfluorfen $(0,48 ; 0,96$ e 1,44$)$ e a formulação comercial de atrazine + metolachlor $(1,25 ; 2,50$; e 3,75$)$, três repetições. Os herbicidas aplicados no experimento instalado em condições de pós-emergência da forrageira, com as respectivas doses em $\mathrm{kg} \mathrm{ha}^{-1}$, foram: ametryne $(1,25 ; 2,50$; e 3,75$)$ e oxyfluorfen $(0,48 ; 0,96$; e 1,44$)$, com quatro repetições. Os tratamentos foram distribuídos em blocos ao acaso; sendo que, em ambos os experimentos foram adicionadas as testemunhas (capinada e sem capina), e os cultivares de capim-elefante utilizados em ambos os experimentos foram Cameroon e Pioneiro. A aplicação dos herbicidas em pré-emergência da forrageira foi feita um dia após o plantio com solo úmido; no experimento em pós-emergência do capim-elefante os herbicidas foram aplicados sobre o topo das plantas da cultura forrageira, aos 20 dias após a emergência. Metolachlor e atrazine + metolachlor, em pré-emergência, foram seletivos para os dois cultivares testados. O oxyfluorfen, até $0,96 \mathrm{~kg} \mathrm{ha}^{-1}$, foi seletivo para a cultura forrageira nas aplicações tanto em pré- como em pósemergência. $O$ ametryne, em pós-emergência, também foi seletivo aos cultivares na dose inferior a $2,50 \mathrm{~kg} \mathrm{ha}^{-1} . B$. decumbens e $B$. brizantha foram eficientemente controladas $(90,9 \%)$ em préemergência, exceto na menor dose de metolachlor e atrazine + metolachlor. O controle das dicotiledôneas atingiu 85\% com metolachlor, atrazine + metolachlor e oxyfluorfen, exceto nas menores doses dos produtos. Em pós-emergência, o ametryne, nas doses de 2,50 e 3,75 kg ha-1, e o oxyfluorfen, nas três doses estudadas, proporcionaram controle superior a $90,3 \%$ para B. decumbens, B. brizantha, S. glaziovii e S. urens; todavia, o oxyfluorfen propiciou controle de A. australe e de $D$. tortuosum inferior a $81,0 \%$, e o ametryne, inferior a $75,6 \%$ para $D$. tortuosum. Tanto na aplicação em pré quanto em pós-emergência, o efeito residual de controle estendeu-se até os 90 dias após aplicação dos herbicidas. O capim-elefante tratado com herbicidas aplicados em pré-emergência cresceu mais (36,28 a 42,79\%); em pós-emergência esse crescimento foi menor $(34,78$ a $47,1 \%)$ para o cultivar Pioneiro, quando comparado com a testemunha sem capina. Para o cultivar Cameroon o crescimento foi de 39,90 a 51,30\% quando o herbicida foi aplicado em préemergência e de 39,83 a 46,61\% em pós-emergência. O acúmulo de biomassa seca da parte aérea do cultivar Pioneiro foi maior em pré-emergência (33,22 a 48,85\%) e em pós-emergência $(73,80$ a 76,65\%); para o cultivar Cameroon esse acúmulo foi de 79,63 a 83,95\% em pré-emergência e de 61,92 a $68,21 \%$ em pós-emergência, também em relação à testemunha sem capina. O cultivar Pioneiro mostrou ser mais tolerante à interferência das plantas daninhas que o Cameroon.
\end{abstract}

Palavras-chave: seletividade, eficiência, plantas daninhas, capim-elefante.

ABSTRACT - Two experiments were carried out to evaluate elephant-grass tolerance to different herbicides sprayed alone or in mixtures in pre-and post-emergence crop conditions, and to evaluate the efficiency of these products in controlling $\boldsymbol{B}$. decumbens and other weeds infesting the elephant-grass crops. Herbicide treatments evaluated in the experiment installed in pre-emergence of

Recebido para publicação em 22/10/2001e na forma revisada em 7/8/2002.

2 Eng.-Flor., D.S. em Fitotecnia, Bolsista Recém-Doutor CNPq, Embrapa Gado de Leite. ${ }^{3}$ Pesquisadores da Embrapa Gado de Leite - Rua Eugênio do Nascimento, 610, Dom Bosco, 36038-330 Juiz de Fora-MG, <vilela@cnpgl.embrapa.br>, <ferreira@cnpgl.embrapa.br> e <avanderp@ cnpgl.embrapa.br>. ${ }^{4}$ Professor do Departamento de Fitotecnia da Universidade Federal de Viçosa - UFV, 36571-000 Viçosa-MG. 
the crop, in $\mathrm{kg} \mathrm{ha}^{-1}$ were: metolachlor (1.152; 2.304 and 3.456), oxyfluorfen (0.48; 0.96 and 1.44) and atrazine + metolachlor (1,25; 2,50; e 3,75), plus the controls, in three repetitions; The herbicide treatments evaluated in the experiment installed in post-emergence conditions, in $\mathrm{kg} \mathrm{ha}^{-1}$, were: ametryne $(1.25 ; 2.50$ and 3.75$)$ and oxyfluorfen $(0.48 ; 0.96$ and 1.44$)$, in four repetitions. The treatments were distributed in randomized blocks in both experiments, with added as treatments (weeded and weed-free), using the elephant-grass cultivars Cameroon and Pioneer. Herbicides in post-emergence were applied on the cultivar plant tops, at 20 days after planting, and in the pre-emergence experiment, one day after planting, and the soil was wet at the moment of herbicide application. Metolachlor, atrazine + metolachlor and oxyfluorfen applied in pre-emergence were selective for Pioneer and Cameroon cultivars. Ametryne and oxyfluorfen were also selective for cultivars when sprayed in post-emergence conditions. Because of initial damages to the crop, oxyfluorfen application in the dose of $1.44 \mathrm{~kg} \mathrm{ha}^{-1}$, as well as, in pre-and post-emergence of the crop, combined with ametryne application in the dose of $3.75 \mathrm{~kg} \mathrm{ha}^{-1}$ in post-emergence, must be avoided. B. decumbens and B. brizantha were controlled in $90.9 \%$ in pre-emergence, when intermediate and higher doses of the herbicides were used. Dicotyledonous plant control was $85 \%$ with metolachlor, atrazine + metalachlor and oxyfluorfen, except when the lowest doses were applied. In pre-emergence application, ametryne doses of 2.50 and $3.75 \mathrm{~kg} \mathrm{ha}^{-1}$ and oxyfluorfen in the three doses studied provided a control level over $90 \%$ in B. decumbens, B. brizantha, S. glaziovii and $\mathbf{S}$. urens, while D. tortuosum, and A. australe control was over $77.9 \%$. In either pre-or in post-emergence application, residual effect of weed control was up to 90 days after application. Treatments with preemergence herbicides were $36.2 \%$ higher in cultivar height evaluated in pre-emergence and $34.7 \%$ higher in height in post-emergence, than the treatment weeded. As for above ground shoot dry matter accumulation, cultivars presented mean earnings of $48.8 \%$ in the treatments with pre-emergence herbicides and of $61.9 \%$ in post-emergence herbicides, compared to weeded. The cultivar Pioneer was more tolerant to weed interference than the cultivar Cameroon.

Key words: selectivity, efficiency, weeds and elephant-grass.

\section{INTRODUÇÃO}

O manejo de plantas daninhas na formação de capineira com capim-elefante tem grande importância, uma vez que esta cultura é muito sensivel à sua interferência durante a fase de implantação, que ocorre no período chuvoso, sob temperaturas elevadas, favorecendo o estabelecimento mais rápido de várias espécies daninhas, principalmente gramíneas. Assim, a ausência de controle dessas invasoras ou o manejo inadequado nos estágios iniciais de crescimento da cultura do capim-elefante podem implicar perdas acentuadas na produtividade.

As plantas daninhas que convivem com as forrageiras reduzem seu valor nutricional. Além disso, essas plantas, quando ingeridas, contribuem com menores proporções de proteínas e sais minerais que as forrageiras, podendo também disseminar sementes destas para outros locais (Peters \& Peters, 1992).

Brachiaria decumbens, quando infesta solo cultivado com capineira de capim-elefante, torna-se uma séria planta daninha, porque possui reprodução por sementes e através de rizomas (Lorenzi, 1982). Suas sementes germinam durante um longo período após o revolvimento do solo, tornando os métodos de controle pouco eficientes (Lorenzi, 1994). Essa descontinuidade no processo germinativo acarreta também ineficiência no controle químico, pois o efeito residual dos herbicidas no solo não cobre todo o período de germinação.

A eficiência dos herbicidas pode ser uma variável, principalmente em função das espécies de plantas daninhas, das condições do ambiente e da época de aplicação (Merotto Jr. et al., 1997). De acordo com Kapusta et al. (1994), os herbicidas aplicados em pré-emergência podem ter sua eficiência comprometida em razão da cobertura do solo com resíduos vegetais, das alterações da textura, das características químicas e dos níveis de umidade do solo; para os herbicidas aplicados em pós-emergência, a eficiência pode estar condicionada às condições climáticas no momento da aplicação e ao estágio de desenvolvimento das plantas daninhas.

Existem poucos relatos na literatura sobre técnicas de controle do capim-braquiária na formação de pastagens de capim-elefante, por serem espécies morfológica e fisiologicamente próximas. Acredita-se que o controle eficaz 
dessa invasora requer herbicida com potencial residual suficientemente longo para cobrir todo o período germinativo. Este trabalho objetivou avaliar a tolerância do capim-elefante a herbicidas e misturas aplicados em pré e pós-emergência e a eficiência desses produtos no controle de $B$. decumbens e outras espécies daninhas.

\section{MATERIAL E MÉTODOS}

Os experimentos foram conduzidos no Campo Experimental de Coronel Pacheco, Coronel Pacheco-MG, pertencente à Embrapa Gado de Leite, em um Podzólico VermelhoAmarelo Câmbico, fase terraço, textura francoargiloso-arenosa, constituído por $36 \%$ de areia grossa, $17 \%$ de areia fina, $13 \%$ de silte e $34 \%$ de argila (EMBRAPA, 1997), sendo o teor de matéria orgânica de 2,11\% (Defelipo \& Ribeiro, 1981) e o $\mathrm{pH} 6,1$.

A área de pastagem era coberta com $80 \%$ de B. decumbens e $20 \%$ de Brachiaria brizantha. Para eliminar a propagação vegetativa da braquiária, aplicou-se $1,44 \mathrm{~kg} \mathrm{ha}^{-1}$ de glyphosate e, 15 dias após, o solo foi arado, gradeado e, dois dias antes do plantio, novamente gradeado. Os sulcos de $0,20 \mathrm{~m}$ de profundidade foram adubados com $100 \mathrm{~kg} \mathrm{ha}^{-1}$ de $\mathrm{P}_{2} \mathrm{O}_{5}$ ha $^{-1}$, fonte superfosfato simples; em seguida, os colmos inteiros de capim-elefante foram colocados em linha dupla. Posteriormente, estes colmos foram cortados com facão, deixando-se pedaços de caule com cerca de 0,40 $\mathrm{m}$ de comprimento, sendo, em seguida, cobertos com $0,15 \mathrm{~m}$ de solo. Os cultivares plantados foram Pioneiro e Cameroon.

As parcelas experimentais foram constituídas de quatro fileiras de $6,0 \mathrm{~m}$ de comprimento, espaçadas de $0,75 \mathrm{~m}$ entre si, sendo as duas fileiras centrais, situadas a menos de $0,50 \mathrm{~m}$ de cada extremidade, consideradas área útil. O período de emergência da cultura foi de aproximadamente 12 dias.

A aplicação dos herbicidas em pré-emergência foi realizada em solo umedecido um dia após o plantio das mudas do capim-elefante. Em pós-emergência, os produtos foram aplicados sobre o topo da cultura, aos 20 dias após a emergência do capim-elefante. Em ambos os experimentos, utilizou-se pulverizador costal, com pressão constante de $30 \mathrm{lb} \mathrm{pol}^{-2}$, equipado com três bicos 110.03, e consumo de calda equivalente a $260 \mathrm{~L} \mathrm{ha}^{-1}$.
A temperatura e a umidade relativa do ar foram de $23{ }^{\circ} \mathrm{C}$ e $84 \%$, respectivamente, e a velocidade do vento de $2,5 \mathrm{~km} \mathrm{~h}^{-1}$, entre $8 \mathrm{~h}$ e 9h25, no experimento de pré-emergência, ao passo que nos experimentos de pós-emergência a temperatura foi de $24^{\circ} \mathrm{C}$, a umidade relativa do ar de $79 \%$ e a velocidade do vento de $3,0 \mathrm{~km} \mathrm{~h}^{-1}$, entre $8 \mathrm{~h}$ e $9 \mathrm{~h} 35$.

Os efeitos dos herbicidas na cultura foram avaliados atribuindo-se notas de acordo com sintomas visuais de toxicidade dos herbicidas, aos 10 e 30 dias após aplicação (DAA), em ambos os experimentos. Foi utilizada a escala EWRC (Frans, 1972), com valores de 0 a 100\%, em que 0 equivale a nenhum dano visivel $\mathrm{e}$ 100 à morte da planta.

A avaliação de controle das espécies invasoras nos experimentos foi realizada por $\mathrm{m}^{2}$ da área útil, aos 30, 60 e 90 DAA, adotando-se a escala visual de 0,0 (ausência de controle) a 100 (controle total). No experimento onde os herbicidas foram aplicados em pré-emergência, as principais espécies, em porcentagem, eram: $48,9 \%$ de $B$. decumbens, $14,9 \%$ de $B$. brizantha, $12,8 \%$ de Sida glaziovii, 7,6\% de Sida urens, $8,1 \%$ de Desmodium tortuosum e 7,7\% de Acanthospermun australe. Semelhante infestação foi observada na aplicação em pós-emergência: $44,5 \%$ de $B$. decumbens, $17,0 \%$ de B. brizantha, $12,8 \%$ de S. glaziovii, $5,0 \%$ de S. urens, $11,5 \%$ de $D$. tortuosum e $9,2 \%$ de A. australe. Em ambos os experimentos, as plantas daninhas do tratamento adicional (parcela capinada) foram controladas mensalmente, com enxada, até os 90 DAA.

Os experimentos com os cultivares Cameroon e Pioneiro foram instalados no delineamento em blocos casualizados. Em préemergência, foram aplicados 22 tratamentos (18 tratamentos com herbicidas mais quatro testemunhas), em três repetições. Os herbicidas avaliados, em $\mathrm{kg} \mathrm{ha}^{-1}$, foram: metolachlor $(1,152 ; 2,304$; e 3,456$)$, oxyfluorfen $(0,48 ; 0,96$; e 1,44 ) e a formulação atrazine + metolachlor $(1,25 ; 2,50$; e 3,75$)$, acrescentados das testemunhas (sem e com capina). A altura da planta e a biomassa foram comparadas pelo teste $\mathrm{F}$ $(\mathrm{P}<0,05)$, bem como as testemunhas. O efeito do herbicida foi comparado com cada testemunha pelo teste de Dunnett, a 5\% de probabilidade, e expresso em porcentagem de variação. 
As doses de cada herbicida foram testadas por meio do teste $\mathrm{F}(\mathrm{P}<0,05)$. Em pós-emergência, foram aplicados 16 tratamentos, em quatro repetições, correspondendo a três doses, em $\mathrm{kg} \mathrm{ha}^{-1}$, de ametryne $(1,25 ; 2,50 ;$ e 3,75$)$ e de oxyfluorfen $(0,48 ; 0,96$; e 1,44$)$ e duas testemunhas (capinada e sem capina). A altura e a biomassa das plantas, bem como as das testemunhas, foram comparadas pelo teste $\mathrm{F}$ $(\mathrm{P}<0,05)$. O efeito dos herbicidas foi comparado com cada testemunha pelo teste de Dunnett, a 5\% de probabilidade, e expresso em porcentagem de variação. As doses de cada herbicida foram testadas por meio do teste $\mathrm{F}$ $(\mathrm{P}<0,05)$.

\section{RESULTADOS E DISCUSSÃO}

\section{Tolerância do capim-elefante e eficácia dos herbicidas aplicados em pré-emergência}

O metolachlor e a formulação atrazine + metolachlor, nas doses avaliadas, não provocaram sintomas de toxicidade nos cultivares aos 10 e 30 DAA (Tabela 1). No entanto, o oxyfluorfen, nas três doses avaliadas, provocou manchas necróticas nos dois cultivares. A dose de $1,44 \mathrm{~kg} \mathrm{ha}^{-1}$ proporcionou toxicidade semelhante $(23,2$ a $22,4 \%)$, nos cultivares Pioneiro e Cameroon, aos 10 DAA, na escala de 0 a 100\%; aos 30 DAA, a toxicidade foi muito baixa $(4,7$ a $6,5 \%)$. Os meristemas apicais da cultura não foram afetados pelo oxyfluorfen mesmo na dose mais elevada $\left(1,44 \mathrm{~kg} \mathrm{ha}^{-1}\right)$, embora 0 crescimento das plantas tenha sido menor. Esse efeito pode estar relacionado ao fato de, com a maior dose de oxyfluorfen $\left(1,44 \mathrm{~kg} \mathrm{ha}^{-1}\right)$, a capacidade de adsorção ter sido maior, proporcionando tal toxicidade, já que o teor de argila é de $34 \%$ e o de matéria orgânica de $2,11 \%$. Segundo Rodrigues \& Almeida (1998) o oxyfluorfen é fortemente adsorvido pelos colóides do solo, e isso facilitou a maior concentração deste herbicida na região de emergência da planta, principalmente na aplicação da maior dose.

O metolachlor, na dose de 2,304 $\mathrm{kg} \mathrm{ha}^{-1}$, apresentou eficiência de controle das gramíneas em torno de 90,9\%, e as dicotiledôneas, em torno de $80 \%$ (Tabela 2). O oxyfluorfen, na dose de $0,48 \mathrm{~kg} \mathrm{ha}^{-1}$, propiciou controle ótimo $(92,4 \%)$ para $B$. decumbens e $B$. brizantha, enquanto para as espécies de folhas largas o controle foi de $95,6 \%$ na dose de $0,96 \mathrm{~kg} \mathrm{ha}^{-1}$, exceto para $D$. tortuosum e $A$. australe, lembrando que $B$. decumbens foi a espécie dominante com maior freqüência na área experimental. De acordo com Foloni \& Espindola (1997), $B$. decumbens é controlada, eficientemente, pelo oxyfluorfen em pré-emergência a $0,72 \mathrm{~kg} \mathrm{ha}^{-1}$ até 60 dias após o tratamento. Atrazine + metolachlor, na dose superior a $2,50 \mathrm{~kg} \mathrm{ha}^{-1}$, proporcionou controle eficiente acima de 90,7\% para as gramíneas e, para as espécies de folhas largas, foi inferior a 88,9\%, exceto para A. australe e S. glaziovii.

Tabela 1 - Grau médio de toxicidade (\%), com o respectivo desvio-padrão, avaliado aos 10 e 30 DAA, em resposta às doses dos herbicidas aplicados em pré-emergência nos cultivares Cameroon e Pioneiro

\begin{tabular}{|c|c|c|c|c|c|}
\hline \multirow{2}{*}{ Herbicida } & \multirow{2}{*}{$\begin{array}{c}\text { Dose } \\
\left(\mathrm{kg} \mathrm{ha}^{-1}\right)\end{array}$} & 10 DAA & 30 DAA & 10 DAA & Cameroon \\
\cline { 3 - 6 } & 1,152 & 0,0 & 0,0 & 0,0 & 0,0 \\
\hline \multirow{3}{*}{ Metolachlor } & 2,304 & 0,0 & 0,0 & 0,0 & 0,0 \\
& 3,456 & 0,0 & 0,0 & 0,0 & 0,0 \\
\hline \multirow{3}{*}{ Oxyfluorfen } & 0,48 & $8,6 \pm(1,6)$ & 0,0 & $8,1 \pm(1,3)$ & 0,0 \\
& 0,96 & $14,3 \pm(2,3)$ & 0,0 & $13,1 \pm(2,0)$ & 0,0 \\
Atrazine & 1,44 & $23,2 \pm(2,8)$ & $6,5 \pm(2,7)$ & $22,4 \pm(4,3)$ & $4,7 \pm(1,1)$ \\
+ & 1,25 & 0,0 & 0,0 & 0,0 & 0,0 \\
Metolachlor & 2,50 & 0,0 & 0,0 & 0,0 & 0,0 \\
\end{tabular}


Tabela 2 - Porcentagem de controle de plantas daninhas, por espécie, em $\mathrm{m}^{2}$, avaliada aos 30 DAA, em resposta às doses dos herbicidas aplicados em pré-emergência dos cultivares

\begin{tabular}{|c|c|c|c|c|c|c|c|}
\hline Herbicida & $\begin{array}{c}\text { Dose } \\
\left(\mathrm{kg} \mathrm{ha}^{-1}\right)\end{array}$ & $\begin{array}{l}\text { Brachiaria } \\
\text { decumbens }\end{array}$ & $\begin{array}{c}\text { Brachiaria } \\
\text { brizantha }\end{array}$ & Sida glaziovii & Sida urens & $\begin{array}{c}\text { Desmodium } \\
\text { tortuosum }\end{array}$ & $\begin{array}{c}\text { Acanthospermun } \\
\text { australe }\end{array}$ \\
\hline \multirow{3}{*}{ Metolachlor } & 1,152 & 71,0 & 69,2 & 68,3 & 67,1 & 62,2 & 82,7 \\
\hline & 2,304 & 92,2 & 90,9 & 87,2 & 80,2 & 71,0 & 90,6 \\
\hline & 3,456 & 97,1 & 95,9 & 92,9 & 90,4 & 80,1 & 95,0 \\
\hline \multirow{3}{*}{ Oxyfluorfen } & 0,48 & 93,1 & 92,4 & 84,2 & 85,6 & 71,3 & 70,4 \\
\hline & 0,96 & 97,1 & 95,9 & 100,0 & 95,6 & 84,4 & 88,8 \\
\hline & 1,44 & 98,8 & 97,9 & 100,0 & 100,0 & 95,0 & 94,0 \\
\hline \multirow{3}{*}{$\begin{array}{c}\text { Atrazine } \\
+ \\
\text { Metolachlor }\end{array}$} & 1,25 & 84,6 & 83,2 & 80,0 & 85,4 & 81,9 & 73,4 \\
\hline & 2,50 & 95,1 & 92,4 & 88,9 & 93,0 & 90,7 & 84,8 \\
\hline & 3,75 & 97,1 & 95,9 & 95,3 & 96,7 & 97,7 & 95,1 \\
\hline $\begin{array}{l}\text { Testemunha } \\
\text { sem capina }\end{array}$ & - & 0,0 & 0,0 & 0,0 & 0,0 & 0,0 & 0,0 \\
\hline
\end{tabular}

Os resultados da eficiência de controle, aos 60 e 90 DAA, foram semelhantes àqueles obtidos aos 30 DAA, ou seja, o número de plantas daninhas ficou estacionário, em virtude da ação residual dos herbicidas no solo, juntamente com o sombreamento da cultura, a qual, aos 60 DAA, apresentava altura com mais de $1 \mathrm{~m}$, cobrindo totalmente o solo.

Aos 90 DAA, o cultivar Cameroon cresceu de 39,9 a $51,3 \%$, e o cultivar Pioneiro, de 36,28 a $42,79 \%$ r, em relação à testemunha sem herbicida. Pelo fato de controlar as plantas daninhas, observa-se, na Tabela 3, que houve aumento de 50,26\% na altura do cultivar Cameroon e de 38,6\% no cultivar Pioneiro, em relação à testemunha sem capina. O cultivar Cameroon, quando esteve livre da interferência de plantas daninhas, atingiu maior crescimento que o cultivar Pioneiro.

O cultivar Pioneiro acumulou biomassa seca da parte aérea que variou entre 33,04 e $48,85 \%$, e o cultivar Cameroon, de 79,63 a $83,95 \%$, entre a relação dos tratamentos com herbicidas e a testemunha sem capina, aos 90 DAA. A ausência de plantas daninhas propiciou acúmulo de biomassa seca de 49,11\% para o cultivar Pioneiro e de $83,95 \%$ para o cultivar Cameroon (Tabela 4).

Pelos resultados apresentados, pode-se inferir que o cultivar Pioneiro é mais resistente à interferência das plantas daninhas que o Cameroon. A interferência das plantas daninhas proporcionou perda significativa de altura e biomassa.

\section{Tolerância do capim-elefante e eficácia dos herbicidas aplicados em pós-emergência}

As doses de 3,75 $\mathrm{kg} \mathrm{ha}^{-1}$ de ametryne e de $1,44 \mathrm{~kg} \mathrm{ha}^{-1}$ de oxyfluorfen proporcionaram maior toxicidade, que variou de 21,5 a $28,4 \%$ no cultivar Pioneiro e de 22,6 a 29,6\% no cultivar Cameroon, aos 10 DAA (Tabela 5). Aos 30 DAA, a injúria provocada pelos herbicidas nos cultivares foi reduzida $(8,1$ a $9,5 \%)$, na escala de 0 a $100 \%$. Esses danos não foram constatados nos meristemas apicais.

O experimento de pós-emergência foi instalado ao lado do de pré-emergência, não sendo detectada diferença entre os dois experimentos em relação às principais espécies invasoras predominantes no local. Além disso, $B$. decumbens se apresentou com maior freqüência que as demais espécies na área experimental. Na Tabela 6 , observa-se que o ametryne, nas doses de 2,50 e $3,75 \mathrm{~kg} \mathrm{ha}^{-1}$, e o oxyfluorfen, nas três doses, propiciaram controle acima de 90,3\% tanto nas gramíneas como nas folhas largas, exceto para $D$. tortuosum (70,0 a $81,0 \%)$, em ambos os herbicidas, e A. australe (65,7 a 80,7\%), para o oxyfluorfen. 
A dose de $1,25 \mathrm{~kg} \mathrm{ha}^{-1}$ de ametryne proporcionou controle razoável. Possivelmente, as características químicas e físicas dos herbicidas definiram a forma de absorção e translocação desses dois produtos nas plantas, fazendo com que a eficiência das aplicações seja influenciada pelo estágio de desenvolvimento das plantas daninhas, as quais no início estavam, do desenvolvimento, com até cinco folhas e com bom estado de vigor vegetativo.

Tabela 3 - Altura média dos cultivares Cameroon e Pioneiro, avaliada aos 90 DAA, em resposta às doses dos herbicidas aplicados em pré-emergência

\begin{tabular}{|c|c|c|c|c|c|c|c|}
\hline \multirow{3}{*}{ Herbicida } & \multirow{3}{*}{$\begin{array}{c}\text { Dose } \\
\left(\mathrm{kg} \mathrm{ha}^{-1}\right)\end{array}$} & \multirow{2}{*}{\multicolumn{2}{|c|}{ Altura (m) }} & \multicolumn{4}{|c|}{ \% de variação em relação à: } \\
\hline & & & & \multicolumn{2}{|c|}{ Testemunha sem herbicida } & \multicolumn{2}{|c|}{ Testemunha capinada } \\
\hline & & Cameroon & Pioneiro & Cameroon & Pioneiro & Cameroon & Pioneiro \\
\hline \multirow{3}{*}{ Metolachlor } & 1,152 & $2,70 \mathrm{~B}$ & $3,03 \mathrm{~A}$ & $+39,90 *$ & $+40,93 *$ & $-6,90$ & $+1,68$ \\
\hline & 2,304 & $2,83 \mathrm{~B}$ & $3,05 \mathrm{~A}$ & $+46,63 *$ & $+41,86 *$ & $-2,41$ & $+2,35$ \\
\hline & 3,456 & $2,90 \mathrm{~A}$ & $3,02 \mathrm{~A}$ & $+50,26 *$ & $+40,47 *$ & 0,00 & $+1,34$ \\
\hline \multirow{3}{*}{$\begin{array}{c}\text { Atrazine } \\
+ \\
\text { Metolachlor }\end{array}$} & 1,250 & $2,78 \mathrm{~B}$ & $3,00 \mathrm{~A}$ & $+44,04 *$ & $+39,53 *$ & $-4,14$ & $+0,67$ \\
\hline & 2,500 & $2,83 \mathrm{~B}$ & $3,07 \mathrm{~A}$ & $+46,63 *$ & $+42,79 *$ & $-2,41$ & $+3,02$ \\
\hline & 3,750 & $2,92 \mathrm{~A}$ & $3,05 \mathrm{~A}$ & $+51,30 *$ & $+41,86 *$ & $+0,69$ & $+2,35$ \\
\hline \multirow{3}{*}{ Oxyfluorfen } & 0,480 & $2,92 \mathrm{~A}$ & $3,00 \mathrm{~A}$ & $+51,30 *$ & $+39,53 *$ & $+0,69$ & $+0,67$ \\
\hline & 0,960 & $2,85 \mathrm{~B}$ & $3,05 \mathrm{~A}$ & $+47,67 *$ & $+41,86 *$ & $-1,72$ & $+2,35$ \\
\hline & 1,440 & $2,85 \mathrm{~A}$ & $2,93 \mathrm{~A}$ & $+47,67 *$ & $+36,28 *$ & $-1,72$ & $-1,68$ \\
\hline \multirow{3}{*}{\multicolumn{2}{|c|}{$\begin{array}{l}\text { Testemunha sem capina } \\
\text { Testemunha capinada } \\
\text { Relação entre as testemunhas }\end{array}$}} & $1,93 \mathrm{Bb}$ & $2,15 \mathrm{Ab}$ & & & & \\
\hline & & $2,90 \mathrm{Aa}$ & $2,98 \mathrm{Aa}$ & & & & \\
\hline & & & & $+50,26 *$ & $+38,60 *$ & & \\
\hline
\end{tabular}

Em cada herbicida e cada dose (linha), $\mathbf{A}$ difere de $\mathbf{B}$ pelo teste $\mathrm{F}(\mathrm{P}<0,05)$.

Em cada cultivar (coluna), a difere de b pelo teste $\mathrm{F}(\mathrm{P}<0,05)$.

* Estatisticamente diferente da testemunha pelo teste de Dunnett $(\mathrm{P}<0,05)$.

Tabela 4 - Biomassa seca da parte aérea média dos cultivares Cameroon e Pioneiro, avaliada aos 90 DAA, em resposta às doses dos herbicidas aplicados em pré-emergência

\begin{tabular}{|c|c|c|c|c|c|c|c|}
\hline \multirow{3}{*}{ Herbicida } & \multirow{3}{*}{$\begin{array}{c}\text { Dose } \\
\left(\mathrm{kg} \mathrm{ha}^{-1}\right)\end{array}$} & \multirow{2}{*}{\multicolumn{2}{|c|}{ Biomassa (g) }} & \multicolumn{4}{|c|}{ \% de variação em relação à: } \\
\hline & & & & \multicolumn{2}{|c|}{ Testemunha sem herbicida } & \multicolumn{2}{|c|}{ Testemunha capinada } \\
\hline & & Cameroon & Pioneiro & Cameroon & Pioneiro & Cameroon & Pioneiro \\
\hline \multirow{3}{*}{ Metolachlor } & 1,152 & $4.863,33 \mathrm{~A}$ & $5.000,00 \mathrm{~A}$ & $+80,12 *$ & $+33,22 *$ & $-2,08$ & $-10,66 *$ \\
\hline & 2,304 & $4.863,33 \mathrm{~B}$ & $5.436,67 \mathrm{~A}$ & $+80,12 *$ & $+44,85 *$ & $-2,08$ & $-2,86$ \\
\hline & 3,456 & $4.951,11 \mathrm{~B}$ & $5.543,33 \mathrm{~A}$ & $+83,37 *$ & $+47,69 *$ & $-0,31$ & $-0,95$ \\
\hline \multirow{3}{*}{$\begin{array}{c}\text { Atrazine } \\
+ \\
\text { Metolachlor }\end{array}$} & 1,250 & $4.850,00 \mathrm{~A}$ & $4.993,33 \mathrm{~A}$ & $+79,63 *$ & $+33,04 *$ & $-2,35$ & $-10,78 *$ \\
\hline & 2,500 & $4.873,33 \mathrm{~B}$ & $5.483,33 \mathrm{~A}$ & $+80,49 *$ & $+46,09 *$ & $-1,88$ & $-2,03$ \\
\hline & 3,750 & $4.933,33 \mathrm{~B}$ & $5.570,00 \mathrm{~A}$ & $+82,72 *$ & $+48,40 *$ & $-0,67$ & $-0,48$ \\
\hline \multirow{3}{*}{ Oxyfluorfen } & 0,480 & $4.943,33 \mathrm{~B}$ & $5.533,33 \mathrm{~A}$ & $+83,09 *$ & $+47,42 *$ & $-0,47$ & $-1,13$ \\
\hline & 0,960 & $4.966,67 \mathrm{~B}$ & $5.586,67 \mathrm{~A}$ & $+83,95 *$ & $+48,85 *$ & 0,00 & $-0,18$ \\
\hline & 1,440 & $4.956,67 \mathrm{~B}$ & $5.583,33 \mathrm{~A}$ & $+83,58 *$ & $+48,76 *$ & $-0,20$ & $-0,24$ \\
\hline \multirow{3}{*}{\multicolumn{2}{|c|}{$\begin{array}{l}\text { Testemunha sem capina } \\
\text { Testemunha capinada } \\
\text { Relação entre as testemunhas }\end{array}$}} & $2.700,00 \mathrm{Bb}$ & $3.753,22 \mathrm{Ab}$ & & & & \\
\hline & & $4.966,67 \mathrm{Ba}$ & $5.596,67 \mathrm{Aa}$ & & & & \\
\hline & & & & $+83,95 *$ & $+49,11 *$ & & \\
\hline
\end{tabular}

Em cada herbicida e cada dose (linha), A difere de $\mathbf{B}$ pelo teste $\mathrm{F}(\mathrm{P}<0,05)$.

Em cada cultivar (coluna), a difere de b pelo teste $\mathrm{F}(\mathrm{P}<0,05)$.

* Estatisticamente diferente da testemunha pelo teste de Dunnett $(\mathrm{P}<0,05)$. 
Redução da interferência de Brachiaria decumbens na ...

Tabela 5 - Grau médio de toxicidade (\%), com o respectivo desvio-padrão, avaliado aos 10 e 30 DAA, em resposta às doses dos herbicidas aplicados em pós-emergência nos cultivares Cameroon e Pioneiro

\begin{tabular}{|c|c|c|c|c|c|}
\hline \multirow{2}{*}{ Herbicida } & \multirow{2}{*}{$\begin{array}{c}\text { Dose } \\
\left(\mathrm{kg} \mathrm{ha}^{-1}\right)\end{array}$} & 10 DAA & 30 DAA & \multicolumn{2}{|c|}{ Cameroon $(\%)$} \\
\cline { 3 - 6 } & 1,25 & $9,8 \pm(1,5)$ & 0,0 & $10,4 \pm(1,9)$ & 0,0 \\
\hline \multirow{3}{*}{ Ametryne } & 2,50 & $12,9 \pm(1,8)$ & $4,5 \pm(1,3)$ & $11,2 \pm(1,5)$ & $4,0 \pm(1,0)$ \\
& 3,75 & $21,5 \pm(3,2)$ & $8,1 \pm(2,1)$ & $22,6 \pm(3,5)$ & $8,9 \pm(2,3)$ \\
\hline \multirow{3}{*}{ Oxyfluorfen } & 0,48 & $10,6 \pm(1,8)$ & 0,0 & $9,5 \pm(1,6)$ & 0,0 \\
& 0,96 & $17,6 \pm(2,8)$ & $5,6 \pm(2,0)$ & $16,0 \pm(2,1)$ & $4,2 \pm(1,1)$ \\
& 1,44 & $28,4 \pm(3,9)$ & $9,5 \pm(2,7)$ & $29,6 \pm(4,3)$ & $9,1 \pm(2,1)$ \\
\hline
\end{tabular}

Tabela 6 - Porcentagem de controle de plantas daninhas, por espécie, em $\mathrm{m}^{2}$, avaliada aos 30 DAA, em respostas às doses dos herbicidas aplicados em pós-emergência dos cultivares

\begin{tabular}{|c|c|c|c|c|c|c|c|}
\hline Herbicida & $\begin{array}{c}\text { Dose } \\
\left(\mathrm{kg} \mathrm{ha}^{-1}\right)\end{array}$ & $\begin{array}{c}\text { Brachiaria } \\
\text { decumbens }\end{array}$ & $\begin{array}{c}\text { Brachiaria } \\
\text { brizantha }\end{array}$ & Sida glaziovii & Sida urens & $\begin{array}{c}\text { Desmodium } \\
\text { tortuosum }\end{array}$ & $\begin{array}{c}\text { Acanthospermun } \\
\text { australe }\end{array}$ \\
\hline \multirow{3}{*}{ Ametryne } & 1,25 & 76,7 & 72,0 & 83,0 & 84,2 & 67,7 & 82,7 \\
& 2,50 & 90,3 & 90,7 & 92,5 & 90,4 & 70,0 & 93,6 \\
& 3,75 & 95,7 & 94,3 & 97,1 & 95,6 & 75,6 & 96,0 \\
\hline \multirow{3}{*}{ Oxyfluorfen } & 0,48 & 92,0 & 91,7 & 91,0 & 90,2 & 73,7 & 65,7 \\
& 0,96 & 100,0 & 98,6 & 94,8 & 93,4 & 77,9 & 73,3 \\
\hline Testemunha & 1,44 & 100,0 & 100,0 & 98,0 & 96,6 & 81,0 & 80,7 \\
sem capina & - & 0,0 & 0,0 & 0,0 & 0,0 & & 0,0 \\
\hline
\end{tabular}

Tabela 7 - Altura média dos cultivares Cameroon e Pioneiro, avaliada aos 90 DAA, em resposta às doses dos herbicidas aplicados em pós-emergência

\begin{tabular}{|c|c|c|c|c|c|c|c|}
\hline \multirow{3}{*}{ Herbicida } & \multirow{3}{*}{$\begin{array}{c}\text { Dose } \\
\left(\mathrm{kg} \mathrm{ha}^{-1}\right)\end{array}$} & \multirow{2}{*}{\multicolumn{2}{|c|}{ Altura (m) }} & \multicolumn{4}{|c|}{ \% de variação em relação à: } \\
\hline & & & & \multicolumn{2}{|c|}{ Testemunha sem herbicida } & \multicolumn{2}{|c|}{ Testemunha capinada } \\
\hline & & Cameroon & Pioneiro & Cameroon & Pioneiro & Cameroon & Pioneiro \\
\hline \multirow{3}{*}{ Ametryne } & 1,250 & $1,65 \mathrm{~B}$ & $1,86 \mathrm{~A}$ & $+39,83 *$ & $+34,78 *$ & $-8,84 *$ & $-9,27 *$ \\
\hline & 2,500 & $1,66 \mathrm{~B}$ & $2,03 \mathrm{~A}$ & $+40,68 *$ & $+47,10 *$ & $-8,29$ & $-0,98$ \\
\hline & 3,750 & $1,71 \mathrm{~B}$ & $1,95 \mathrm{~A}$ & $+44,92 *$ & $+41,30 *$ & $-5,52$ & $-4,88$ \\
\hline \multirow{3}{*}{ Oxyfluorfen } & 0,480 & $1,73 \mathrm{~B}$ & $2,01 \mathrm{~A}$ & $+46,61 *$ & $+45,65 *$ & $-4,42$ & $-1,95$ \\
\hline & 0,960 & $1,71 \mathrm{~B}$ & $2,01 \mathrm{~A}$ & $+44,92 *$ & $+45,65 *$ & $-5,52$ & $-1,95$ \\
\hline & 1,440 & $1,73 \mathrm{~B}$ & $1,91 \mathrm{~A}$ & $+46,61 *$ & $+38,41 *$ & $-4,42$ & $-6,83$ \\
\hline \multirow{3}{*}{\multicolumn{2}{|c|}{$\begin{array}{l}\text { Testemunha sem capina } \\
\text { Testemunha capinada } \\
\text { Relação entre as testemunhas }\end{array}$}} & $1,18 \mathrm{Bb}$ & $1,38 \mathrm{Aa}$ & & & & \\
\hline & & $1,81 \mathrm{Ba}$ & 2,05 Aa & & & & \\
\hline & & & & $+53,39 *$ & $+48,55 *$ & & \\
\hline
\end{tabular}

Em cada herbicida e cada dose (linha), A difere de $\mathbf{B}$ pelo teste $\mathrm{F}(\mathrm{P}<0,05)$.

Em cada cultivar (coluna), a difere de $\mathbf{b}$ pelo teste $\mathrm{F}(\mathrm{P}<0,05)$.

* Estatisticamente diferente da testemunha pelo teste de Dunnett $(\mathrm{P}<0,05)$. 
Tabela 8 - Biomassa média dos cultivares Cameroon e Pioneiro, avaliada aos 90 DAA, em resposta às doses dos herbicidas aplicados em pós-emergência

\begin{tabular}{|c|c|c|c|c|c|c|c|}
\hline \multirow{2}{*}{ Herbicida } & \multirow{2}{*}{$\begin{array}{c}\text { Dose } \\
\left(\mathrm{kg} \mathrm{ha}^{-1}\right)\end{array}$} & \multicolumn{3}{|c|}{ Biomassa $(\mathrm{m})$} & \multicolumn{4}{c|}{ \% de variação em relação à: } \\
\cline { 3 - 9 } & & Cameroon & Pioneiro & Cameroon & Pioneiro & Cameroon & Pioneiro \\
\cline { 3 - 9 } & 1,250 & $2.445,00 \mathrm{~B}$ & $3.815,00 \mathrm{~A}$ & $+61,92 *$ & $+73,80 *$ & $-4,77$ & $-2,74$ \\
\multirow{3}{*}{ Ametryne } & 2,500 & $2.522,50 \mathrm{~B}$ & $3.870,00 \mathrm{~A}$ & $+67,05 *$ & $+76,31 *$ & $-1,75$ & $-1,34$ \\
& 3,750 & $2.497,50 \mathrm{~B}$ & $3.837,50 \mathrm{~A}$ & $+65,40 *$ & $+74,83 *$ & $-2,73$ & $-2,17$ \\
\hline \multirow{2}{*}{ Oxyfluorfen } & 0,480 & $2.525,00 \mathrm{~B}$ & $3.877,50 \mathrm{~A}$ & $+67,22 *$ & $+76,65 *$ & $-1,66$ & $-1,16$ \\
& 0,960 & $2.540,00 \mathrm{~B}$ & $3.852,50 \mathrm{~A}$ & $+68,21 *$ & $+75,51 *$ & $-1,07$ & $-1,78$ \\
& 1,440 & $2.512,50 \mathrm{~B}$ & $3.825,00 \mathrm{~A}$ & $+66,39 *$ & $+74,26 *$ & $-2,14$ & $-2,49$ \\
\hline
\end{tabular}

Em cada herbicida e cada dose (linha), $\mathbf{A}$ difere de $\mathbf{B}$ pelo teste $\mathrm{F}(\mathrm{P}<0,05)$.

Em cada cultivar (coluna), a difere de $\mathbf{b}$ pelo teste $\mathrm{F}(\mathrm{P}<0,05)$.

* Estatisticamente diferente da testemunha pelo teste de Dunnett $(\mathrm{P}<0,05)$.

Na avaliação feita aos 60 e 90 DAA, não se observou reinfestação por parte das espécies invasoras presentes; possivelmente isso ocorreu como conseqüência do efeito residual dos herbicidas, e/ou juntamente com o sombreamento da capineira, que, aos 60 DAA, apresentava altura superior a $0,90 \mathrm{~m}$, com intenso fechamento do dossel. Dessa forma, o efeito da germinação das sementes das plantas daninhas foi restrito. Segundo Cruz (1987), B. decumbens pode ser controlada também em pós-emergência inicial, ou seja, depois da emergência e antes do perfilhamento da planta, por meio de herbicidas que tenham ação residual. Essa é uma medida alternativa de aplicação de herbicidas que pode ampliar o período de ação dos produtos com relativa persistência no solo, além de controlar as plantas já emergidas.

O acúmulo de biomassa seca da parte aérea das plantas tratadas com herbicidas foi maior, variando de 61,92 a 68,21\% para Cameroon e de 73,80 a $76,65 \%$ para Pioneiro, em comparação com a testemunha sem capina. O mesmo ocorreu com o tratamento adicional (controle); este apresentou maior biomassa seca da parte aérea, que foi de $70,03 \%$ no cultivar Cameroon e de 78,7\% no cultivar Pioneiro, em relação à testemunha sem capina (Tabela 8). Pelos resultados, o cultivar Pioneiro mostrou ser mais resistente à interferência das plantas daninhas que o Cameroon.

\section{LITERATURA CITADA}

CRUZ, L. S. P. Controle de Brachiaria decumbens Stapf em cana-de-açúcar com oryzalin e tebuthiron. Açúcar Álcool Subp., v. 5, n. 4, p. 19-22, 1987.

DEFELIPO, B. V.; RIBEIRO, A. C. Análise química do solo (metodologia). Viçosa, MG: Universidade Federal de Viçosa, 1981. 17 p. (Boletim de extensão, 29).

EMPRESA BRASILEIRA DE PESQUISA AGROPECUÁRIA- EMBRAPA. Serviço Nacional de Levantamento e Conservação de Solos (Rio de Janeiro, RJ). Manual e métodos de análise de solo. Rio de Janeiro: 1997. $212 \mathrm{p}$.

FOLONI, L. L.; ESPINDOLA, C. R. Utilização do sulfentrazone no controle de plantas daninhas em cultivo mínimo de eucalipto. In: CONGRESSO BRASILEIRO DA CIÊNCIA DAS PLANTAS DANINHAS, 1997, Caxambu. Resumos... Caxambu: SBCPD, 1997. p. 291.

FRANS, R. W. Measuring plant response. In: WILKINSON, R.E. (Ed.) Research methods in weed science. Puerto Rico: Weed Science Society, 1972. p. 28-41. 
KAPUSTA, G. et al. Effect of nicosulfuton rate, adjuvant, and weed size on annual weed control in corn (Zea mays). Weed Technol., v. 8, n. 4, p. 696-702, 1994.

LORENZI, H. Plantas daninhas do Brasil: terrestres, aquáticas, parasitas, tóxicas e medicinais. Nova Odessa: Edição do Autor, 1982. 425 p.

LORENZI, H. Manual de identificação e controle de plantas daninhas: plantio direto e convencional. 4.ed. Nova Odessa: 1994. 220 p.
MEROTTO Jr., A.; ALMEIDA, M. L.; FUCHS, O. Aumento do rendimento de grãos de milho através do aumento da população de plantas. Ci. Rural, v. 27, n. 4, p. 549-554, 1997.

PETERS, E.J.; PETERS, R.A. Weeds and control. In: ALFALFA science and technology. Madison: American Society of Agronomy, 1992. 812 p.

RODRIGUES, B. N.; ALMEIDA, F. S. Guia de herbicidas. 4.ed. Londrina: 1998. 648 p. 